\title{
Prevalence of Anemia: Figures at the Time of Pregnancy Detection in Our Hospital
}

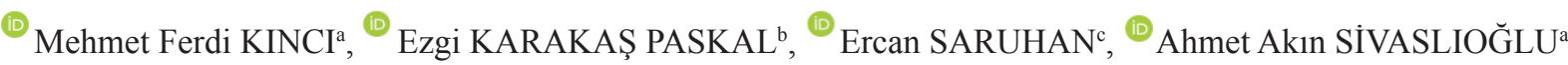 \\ aDepartment of Obstetrics and Gynecology, Muğla Sitkı Koçman University Training and Research Hospital, Muğla, TURKEY \\ ${ }^{b}$ Department of Obstetrics and Gynecology, Başakşehir Çam ve Sakura City Hospital, İstanbul, TURKEY \\ ${ }^{\mathrm{c}}$ Department of Medical Biochemistry, Muğla Sitkı Koçman University, Faculty of Medicine, Muğla, TURKEY
}

\begin{abstract}
Objective: The aim of this study was to identify the prevalence of anemia in pregnant women at the time of pregnancy detection. Material and Methods: A retrospective study was conducted on 11582 women who had diagnosis of pregnancy between 2012 and 2019. Patients were divided into 3 groups according to the hemoglobin (Hb) levels of patients by their age. Pregnant women $\leq 19$ years of age were defined as Group 1, 20-34 years of age as Group 2, and $\geq 35$ years of age as Group 3. Anemia was defined as a hemoglobin level of $<11$ $\mathrm{g} / \mathrm{dL}$. Results: The overall prevalence of anemia at the time of pregnancy diagnosis was $21.95 \%$. The average $\mathrm{Hb}$ level was $11.7 \pm 1.4 \mathrm{~g} / \mathrm{dL}$, $12 \pm 1.4 \mathrm{~g} / \mathrm{dL}, 12 \pm 1.4 \mathrm{~g} / \mathrm{dL}$, and $11.9 \pm 1.4 \mathrm{~g} / \mathrm{dL}$ in Groups $1,2,3$, and entire study cohort, respectively. When severity of anemia was evaluated within the groups; Group 1 consists of $21.96 \%$ (n:181) mild anemia, 4.73\% (n:39) moderate anemia, and 1.69\% (n:14) severe anemia, Group 2 consists of $16.33 \%$ (n:1459) mild anemia, 4.44\% (n:397) moderate anemia, and 0.67\% (n:60) severe anemia, and Group 3 consists of $16.83 \%$ (n:307) mild anemia, 4.05\% (n:74) moderate anemia, and 0.65\% (n:12) severe anemia cases. Conclusion: The prevalence of anemia during pregnancy was different in age groups. Therefore, each clinic should divide its pregnant women into different age groups and evaluate the frequency of anemia.
\end{abstract}

Keywords: Anemia; pregnancy; adolescent; advanced maternal age

Anemia is one of the most common pregnancyrelated complications. ${ }^{1,2}$ According to World Health Organization (WHO) definitions, pregnant women with hemoglobin $(\mathrm{Hb})$ values less than $11 \mathrm{~g} / \mathrm{dL}$ are considered anemic who are further classified as mild (9.5-10.9 g/dL), moderate (7-9.4 g/dL), and severe (below $7 \mathrm{~g} / \mathrm{dL}$ ). The prevalence of anemia depends on multiple factors including the development status of the living place, genetic traits, lifestyles, and eating habits of people. During pregnancy, anemia is detected in $35 \%$ to $75 \%$ of pregnant women in developing countries in comparison to $18 \%$ in developed countries. ${ }^{3}$ Pregnancy-related anemia most often results from acute blood loss taking place during labor and arises in the form of iron-deficiency anemia (IDA). ${ }^{4}$ Maternal anemia in pregnancy is commonly associated with preterm delivery, premature birth, and poor pregnancy outcome. ${ }^{5,6}$ Therefore, Republic of Turkey Ministry of Health recommends starting iron therapy in all pregnant women (regardless of they are anemic or not) at a dose of 40-60 $\mathrm{mg} /$ day. $^{7}$

Adolescent pregnancy is childbearing at the age period of 10 to 19 years $;{ }^{8}$ and pregnant women over the age of 35 are considered to be at advanced maternal age (AMA) according to WHO gestational age classification. ${ }^{9}$ Recent studies demonstrated that adolescent pregnancies are prone to more than a 2 -fold increased rate of anemia due to nutritional problems in comparison to pregnancies at other age groups. In adolescent pregnancies complicated by anemia, there

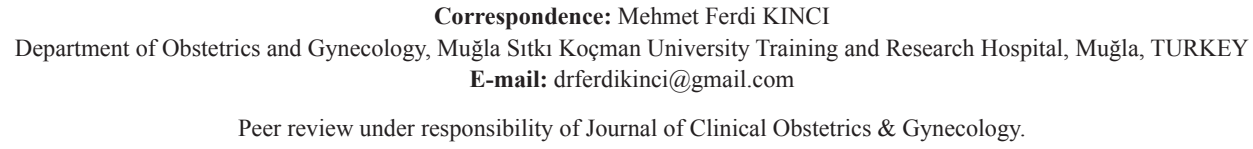


is a risk of low birth weight, preterm birth, neonatal morbidity and increased mortality. ${ }^{10}$ On the other hand, pregnancies at AMA are closely related to complications. Due to complications that may occur during delivery (uterine atonia, preeclampsia, invasive placenta), maternal morbidity and mortality may increase. ${ }^{11} \mathrm{Hb}$ levels become important at the later stage of pregnancy, closer to the date of confinement.

In the present study, we aimed to determine the prevalence of anemia in adolescent age, normal age, and AMA pregnancies followed up in our hospital.

\section{METHODS}

This is a retrospective study conducted in Muğla Sitk1 Koçman University Training and Research Hospital, Department of Gynecology and Obstetrics. Approval of the local ethics committee was obtained for this study (Date:18.06.2020, Decision No:06/3). The study was conducted in accordance with the Helsinki Declaration.

We enrolled 11,582 women who referred to our hospital between 2012 and 2019, for whom the diagnosis of pregnancy was established upon detection of fetal heartbeats with ultrasonography (USG). Routine complete blood counts (CBC) were carried out for all pregnant women. Patients' data were accessed through our internal data processing system (Karmed Data Processing Systems). Age and $\mathrm{Hb}$ level were recorded for each patient at the first antenatal visit.

Blood samples were collected into ethylene diamine tetraacetic acid (EDTA) containing blood tubes by venipuncture once patients were admitted to the clinic. CBC parameters were analyzed using a Sysmex XN-1000 hematology analyzer (Sysmex, Kobe, Japan). In accordance with the WHO recommendations, pregnant women with $\mathrm{Hb}$ values less than 11 $\mathrm{g} / \mathrm{dL}$ were considered anemic and they were further classified as mild (9.5-10.9 g/dL), moderate (7-9.4 $\mathrm{g} / \mathrm{dL}$ ), and severe (below $7 \mathrm{~g} / \mathrm{dL}$ ). ${ }^{12}$

Patients were divided into 3 groups according to the $\mathrm{Hb}$ levels of patients by their age. Such that, patients $\leq 19$ years of age were defined as Group 1, 2034 years of age as Group 2, and $\geq 35$ years of age as Group 3. Hb levels were compared in the entire cohort of patients and among the age groups.
Statistical analysis was done using SPSS software (IBM SPSS Statistics, Version 22.0. Armonk, NY: IBM Corp). Our null hypothesis stated that there were no differences in the levels of $\mathrm{Hb}$ among the age groups. Shapiro-Wilk test was used to evaluate the distribution of variables. Variables with a normal distribution were presented as mean \pm standard deviation (SD) and non-normally distributed variables were presented as median and quartiles $\left(25^{\text {th }}-75^{\text {th }}\right.$ percentiles). Differences among the groups for each parameter were analyzed by one-way analysis of variance (ANOVA) using Tukey correction for normally distributed parameters and Kruskal-Wallis test for non-normally distributed parameters. P-values less than 0.05 were considered statistically significant.

\section{RESULTS}

A total of 11,582 pregnant women were included in our study. The mean age of the patients was $28.0 \pm 6.0$ years (min 13 and max 56). Groups 1, 2, and 3 were comprised of 824, 8934, and 1824 patients, respectively. The average $\mathrm{Hb}$ level was $11.7 \pm 1.4 \mathrm{~g} / \mathrm{dL}, 12 \pm 1.4 \mathrm{~g} / \mathrm{dL}, 12 \pm 1.4 \mathrm{~g} / \mathrm{dL}$, and $11.9 \pm 1.4 \mathrm{~g} / \mathrm{dL}$ in Groups 1, 2, 3, and entire study cohort, respectively. In Groups 1, 2, and 3, the average ages were $18.0 \pm 1.0,27.0 \pm 4.0$, and $38.0 \pm 3.0$ years, respectively (Table 1 ).

Based on the screening tests in the first trimester, $16.81 \%$ (n:1947) of women had mild anemia, $4.40 \%$ (n:510) had moderate anemia, and 0.74\% (n:86) had severe anemia (Table 2). The overall prevalence of anemia at the time of pregnancy diagnosis was $21.95 \%$ ( $\mathrm{n}: 2543)$. When severity of anemia was evaluated within the groups; Group 1 consists of $21.96 \%$ (n:181) mild anemia, 4.73\% (n:39) moderate anemia, and 1.69\% (n:14) severe anemia, Group 2 consists of $16.33 \%$ (n:1459) mild anemia, 4.44\% (n:397) moderate anemia, and $0.67 \%$ (n:60) severe anemia, and Group 3 consists of $16.83 \%$ (n:307) mild anemia, $4.05 \%$ (n:74) moderate anemia, and $0.65 \%$ (n:12) severe anemia cases (Table 3)

$\mathrm{Hb}$ levels of pregnant women were lower in Group 1 compared to other age groups as presented in Table 1 and Figure $1(\mathrm{p}<0.001)$. 


\begin{tabular}{|lcccc|}
\hline \multicolumn{4}{|c|}{ TABLE 1: Hemoglobin levels of pregnant women in different age groups. } \\
\hline & Group 1 & Group 2 & Group 3 & Entire group \\
& $(\leq 19$ age, $\mathrm{n}: \mathbf{8 2 4})$ & $(\mathbf{2 0 - 3 5}$ age, $\mathrm{n}: 8934)$ & $(\geq 35$ age, $\mathrm{n}: 1824)$ & $(\mathbf{1 3 - 5 6}$ age, $\mathrm{n}: 11582)$ \\
Hemoglobin $(\mathrm{g} / \mathrm{dL})$ & $* 11.7 \pm 1.4$ & $12 \pm 1.4$ & $12 \pm 1.4$ & $11.9 \pm 1.4$ \\
Age (years) & $18 \pm 1$ & $27 \pm 4$ & $38 \pm 3$ & $28 \pm 6$ \\
Data are presented as mean \pm SD & & & & \\
\hline
\end{tabular}

* indicating statistically significant differences between groups

\begin{tabular}{|c|c|c|c|c|}
\hline & $\begin{array}{l}\text { Severe anemia } \\
\qquad(H b<7)\end{array}$ & $\begin{array}{l}\text { Moderate anemia } \\
\quad(7 \leq \mathrm{Hb}<9.5)\end{array}$ & $\begin{array}{l}\text { Mild anemia } \\
(9.5 \leq \mathrm{H} b<11)\end{array}$ & $\begin{array}{c}\text { No anemia } \\
(11 \leq \mathrm{Hb})\end{array}$ \\
\hline $\mathrm{n}, \%$ & $86,0.74 \%$ & $510,4.40 \%$ & $1947,16.81 \%$ & $9039,78.05 \%$ \\
\hline Hemoglobin $(\mathrm{g} / \mathrm{dL})$ & $7.4 \pm 0.6$ & $8.9 \pm 0.4$ & $10.3 \pm 0.4$ & $12.5 \pm 0.9$ \\
\hline Age (years) & *26 26 & $28 \pm 6$ & $28 \pm 6$ & $28 \pm 6$ \\
\hline \multicolumn{5}{|c|}{ Data are presented as mean $\pm \mathrm{SD}$} \\
\hline
\end{tabular}

* indicating statistically significant differences between groups

\begin{tabular}{|c|c|c|c|c|c|c|c|c|}
\hline & \multicolumn{3}{|c|}{$\begin{array}{c}\text { Group } 1 \\
\text { (Age } \leq 19 \text { years, } \mathrm{n}: 234)\end{array}$} & \multicolumn{2}{|c|}{$\begin{array}{c}\text { Group } 2 \\
(20 \leq \text { Age }<35 \text { years, } n: 1916)\end{array}$} & \multicolumn{3}{|c|}{$\begin{array}{c}\text { Group } 3 \\
\text { (Age } \geq 35 \text { years, } n: 393 \text { ) }\end{array}$} \\
\hline & Sever & Moderate & Mild & Severe & Moderate Mild & Severe & Moderate & Mild \\
\hline $\mathrm{n}, \%$ & $14,1.7$ & $39,4.7$ & $181,22.0$ & $60,0.7$ & $397,4.4 \quad 1459,16.3$ & $12,0.7$ & $74,4.1$ & $307,16.8$ \\
\hline Hemoglobin (g/dL) & $7.5 \pm 0.3$ & $8.8 \pm 0.4$ & $10.3 \pm 0.4$ & $7.3 \pm 0.6$ & $8.9 \pm 0.4 \quad 10.3 \pm 0.4$ & $7.2 \pm 0.9$ & $8.9 \pm 0.4$ & $10.3 \pm 0.4$ \\
\hline Data are presented & mean $\pm S D$ & & & & & & & \\
\hline
\end{tabular}

\section{DISCUSSION}

Anemia is a common public health concern across the globe. Particularly in women of reproductive age, iron deficiency is the most frequent reason for anemia. For this reason, development status in a country has strong connections with the anemia prevalence among its inhabitants. According to the WHO data, the prevalence of anemia is lowest in North America where a rate of $6 \%$ was reported compared to $14 \%$ in Europe. ${ }^{13}$ This rate reaches up to $75 \%$ in Gambia. ${ }^{12}$ Studies conducted in our country have come up with various results.

In the study by Davas et al. implemented in 2006 , an anemia rate of $74.1 \%$ was identified. The study with the lowest rate of anemia was published in 2016 and was conducted by Küçükceren and colleagues ${ }^{14}$ who investigated 200 patients in Ankara and detected $13.15 \%$ of them had anemia. They identified risk factors of anemia as duration of shorter

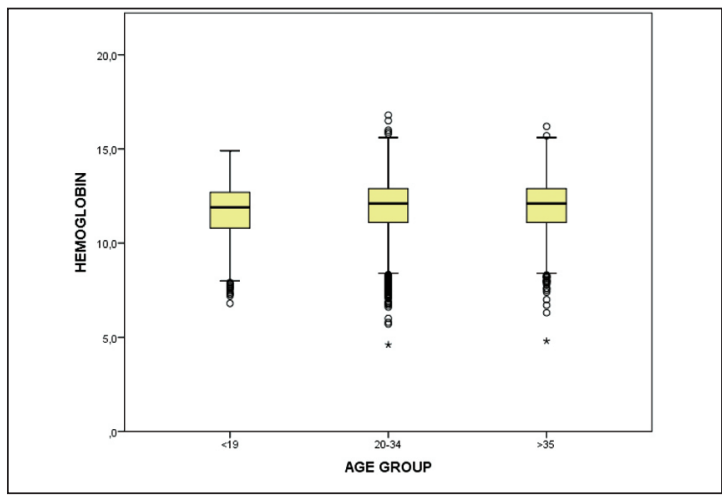

FIGURE 1: Comparison of hemoglobin levels in different age groups.

than 2 years between two successive pregnancies and tea consumption in large quantities. In our study, anemia rate in the general population was $21.95 \%$. Of note, our sample size was quite greater than the number of patients included in previous studies.

When we reviewed the studies which have reported mean $\mathrm{Hb}$ levels, the lowest levels were documented by Harma et al. who conducted a study in 
Sanliurfa among grand multiparous women with an average level of $10.4 \pm 1.9 \mathrm{~g} / \mathrm{dL} .{ }^{15}$ Mean Hb levels determined in studies of Küçükceren et al. and Kesgin et al. were $12.7 \pm 0.93 \mathrm{~g} / \mathrm{dL}$ and $12.6 \pm 1.02 \mathrm{~g} / \mathrm{dL}$, respectively. The above-mentioned figures are the highest ones among the results of the articles we have reviewed. In our cohort, the mean $\mathrm{Hb}$ level was $11.9 \pm 1.4 \mathrm{~g} / \mathrm{dL}$. Our value is similar to those of Göker et al. who included 1,900 patients residing in Manisa and Çitıl et al. who measured $\mathrm{Hb}$ levels in 311 women in Tokat $(11.9 \pm 1.3 \mathrm{~g} / \mathrm{dL}, 11.9 \pm 1.2 \mathrm{~g} / \mathrm{dL}){ }^{16,17}$

There is a limited number of studies that analyzed the relationship between anemia and age groups in pregnant women such as our study. In a study from Izmir, Taner et al. determined rate of anemia as $41.6 \%{ }^{18}$ The authors listed maternal age over 35 years as a risk factor for anemia. In the study conducted by Öztürk et al. in Ankara, the prevalence of anemia among pregnant women over the age of 35 years was $19 \% .{ }^{19}$ In our study, the prevalence of anemia in AMA pregnancies was $21.53 \%$ and in entire pregnant population was $21.95 \%$. Our results were in parallel with the results of Öztürk et al. Kavak et al. investigated adolescent pregnancies in Elazig and determined the anemia frequency as $18.2 \%{ }^{20}$ On the other hand, the prevalence of anemia in adolescent pregnancies was $28.38 \%$ which was significantly higher than the other age groups in our study $(\mathrm{p}<0.001)$.

Anemia during pregnancy has been associated with a poor obstetric outcome. ${ }^{6}$ Y1ldiz et al. studied 28,600 term births and investigated women who had suffered anemia during pregnancy and their respective outcomes. ${ }^{21}$ The researchers found that infants born from mothers with anemia during pregnancy had reduced birth weight and shorter length at birth. We designed a prevalence study which did not search any pregnancy outcomes. This design characteristic was one of the limitations of our study. Another limitation of our study was the high difference between the number of patients in each group.

\section{CONCLUSION}

Although the prevalence of anemia during pregnancy varies according to many factors, it is still quite common all over the world. For this reason, each clinic should first evaluate its prevalence and then determine the risk factors. It should be taken into account that age is one the most important risk factors. Nutritional supplements should be provided, especially to the adolescent age group.

\section{Source of Finance}

During this study, no financial or spiritual support was received neither from any pharmaceutical company that has a direct connection with the research subject, nor from a company that provides or produces medical instruments and materials which may negatively affect the evaluation process of this study.

\section{Conflict of Interest}

No conflicts of interest between the authors and / or family members of the scientific and medical committee members or members of the potential conflicts of interest, counseling, expertise, working conditions, share holding and similar situations in any firm.

\section{Authorship Contributions}

Idea/Concept: Mehmet Ferdi Kıncl, Ezgi Karakaş Paskal, Ahmet Akın Sivaslıoğlu; Design: Ezgi Karakaş Paskal, Ercan Saruhan; ontrol/Supervision: Ahmet Akın Sivaslıoğlu; Data Collection and/or Processing: Ercan Saruhan, Mehmet Ferdi Kıncl; Analysis and/or Interpretation:Ercan Saruhan, Mehmet Ferdi Kıncl; Literature Review: Ezgi Karakaş Paskal, Mehmet Ferdi Kıncl; Writing the Article: Mehmet Ferdi Kıncl, Ercan Saruhan; Critical Review: Ahmet Akın Sivasloğlu; References and Fundings: Mehmet Ferdi Kıncl, Ezgi Karakaş Paskal; Materials: Ercan Saruhan. 


\section{REFERENCES}

1. Auerbach M, Landy $\mathrm{H}$, Barss VA. Anemia in pregnancy. Uptodate, 2018.

2. Sifakis $\mathrm{S}$, Pharmakides $\mathrm{G}$. Anemia in pregnancy. Ann N Y Acad Sci. 2000;900:12536.[Crossref] [PubMed]

3. World Health Organization. Maternal Health and Safe Motherhood Programme \& World Health Organization. The prevalence of anaemia in women: a tabulation of available information. 2nd ed. Geneva: World Health Organization, 1992.

4. American College of Obstetricians and Gynecologists. ACOG Practice Bulletin No. 95: anemia in pregnancy. Obstet Gynecol. 2008 Jul;112(1):201-7. Erratum in: Obstet Gynecol. 2020;135(1):222.[Crossref] [PubMed]

5. Dalal E, Shah J. A comparative study on outcome of neonates born to anemic mothers versus non anemic mothers. Natl J Med Res. 2014:4:270-3.[Link]

6. Xiong $X$, Buekens $\mathrm{P}$, Alexander $\mathrm{S}$, Demianczuk N, Wollast E. Anemia during pregnancy and birth outcome: a meta-analysis. Am J Perinatol. 2000;17(3):137-46.[Crossref] [PubMed]

7. T.C. Sağlık Bakanlığı, Halk Sağlı̆ı Müdürlüğü. Doğum Sonu Bakım Yönetim Rehberi. 2010.

8. Keskin U, Kıncı MF. [Adolescence Period and Pregnancy]. Turkiye Klinikleri, Family Medi-
cine-Special Topics. 2018;9:33-8.

9. Heffner LJ. Advanced maternal age--how old is too old? N Engl J Med. 2004;351(19):19279.[Crossref] [PubMed]

10. Scholl TO, Hediger ML, Belsky DH. Prenatal care and maternal health during adolescent pregnancy: a review and meta-analysis. $J$ Adolesc Health. 1994;15(6):444-56. [Crossref] [PubMed]

11. Fretts RC, Simpson LL. Effects of advanced maternal age on pregnancy. UpToDate, 2018.[Link]

12. World Health Organization. WHO global database on anaemia. Worldwide prevalence of anaemia 1993-2005. WHO global database on anaemia 2008.[Link]

13. World Health Organization. Maternal health and safe motherhood programme. World, 1996.

14. Küçükceran $H$, Başer DA, Ağadayı $E$, Alsancak AD, Kahveci R. [Iron deficiency anemia prevalence and the factors which cause the iron defiency during pregnancy term in Ankara Akyurt region]. Konuralp Medical Journal. 2018;10(1):13-9.[Crossref]

15. Harma M, Harma M, Yurtseven S, Demir N. [Frequency Of Anemia Among Multiparous Pregnant Women]. Turkiye Klinikleri J Gynecol Obst. 2004;14(1):12-5.
16. Göker A, Yanıkerem E, Birge Ö. [Prevalence of anemia in pregnant women who applied to a training and research hospital in Manisa: a retrospective study]. STED. 2012;21(3):1029.

17. Çıtıl R, Barut SY, Eğri M, Önder Y. [Anemia prevalence and related factors in pregnant women admitted to state hospital]. Çağdaş Tıp Dergisi 2014;4(2):76-83

18. Taner CE, Ekin A, Solmaz U, Gezer C, Çetin $B$, Keleşoğlu M, et al. Prevalence and risk factors of anemia among pregnant women attending a high-volume tertiary care center for delivery. J Turk Ger Gynecol Assoc. 2015;16(4):231-6. [Crossref] [PubMed] [PMC]

19. Öztürk M, Öztürk Ö, Ulubay M, Karaşahin $E$ Özgürtaş T, Yenen M, Aydın A, Fıratıgil F, Bodur S. Anemia prevalence at the time of pregnancy detection. Turk J Obstet Gynecol. 2017;14(3):176-80.[Crossref] [PubMed] [PMC]

20. Kavak EÇ, Kavak SB. The association between anemia prevalence, maternal age and parity in term pregnancies in our city. Perinatal Journal. 2017;25(1):6-10.[Crossref]

21. Yildiz Y, Özgü E, Unlu SB, Salman B, Eyi EG. The relationship between third trimester maternal hemoglobin and birth weight/length; results from the tertiary center in Turkey. $J$ Matern Fetal Neonatal Med. 2014;27(7):72932. [Crossref] [PubMed] 